\title{
New Approach to the Phenomenology of Amorphous Curie-Point Relaxation
}

\begin{abstract}
A. LOVAS
Department of Vehicles Manufacturing and Repairing, Budapest University of Technology and Economics Bertalan Lajos utca 2, Budapest H-1111, Hungary

The possible origin of short range atomic displacements coupled with the irreversible amorphous Curie temperature relaxation $\left(\Delta T_{\mathrm{C}}^{\mathrm{am}}\right)$ in Fe-based glasses is discussed and analyzed on the basis of quenched-in phase reminiscences. The displacements are dominantly symmetry changes, which are governed by the relative stability of fcc and bcc quenched-in phase reminiscences at a given temperature range. Those of elements which cause positive $\Delta T_{\mathrm{C}}^{\mathrm{am}}$ in as quenched state, also cause positive irreversible $\Delta T_{\mathrm{C}}^{\mathrm{am}}$ during structural relaxation. The influence of $\mathrm{Cr}$ addition is just the opposite in this respect.
\end{abstract}

PACS numbers: $75.50 . \mathrm{Kj}, 75.30 . \mathrm{Kz}$

\section{Introduction}

The phenomenological descriptions of structural relaxation, as well as the associated changes in physical properties are sufficiently documented. However, the available phenomenological modeling is less powerful in the explanation of atomic level processes. It is especially true in the case of amorphous Curie point relaxation $\left(\Delta T_{\mathrm{C}}^{\mathrm{am}}\right)$. The irreversible $\Delta T_{\mathrm{C}}^{\mathrm{am}}$ appears usually during the first period of isothermal heat treatments, or when the samples are heated for the $T_{\mathrm{C}}^{\mathrm{am}}$ determination [1]. Short range atomic displacements occur in this process, due to the increasing atomic mobility. The irreversible $T_{\mathrm{C}}^{\mathrm{am}}$ shift is predominantly positive in Fe-based glasses which are coupled also with irreversible free volume decrease (density increase) [2]. Negative, "anomalous" $\Delta T_{\mathrm{C}}^{\mathrm{am}}$ was found in Cr-containing amorphous alloys $[3,4]$. Due to the diversity of experimental results the micro-mechanism of irreversible $T_{\mathrm{C}}^{\mathrm{am}}$ shift is not yet explained sufficiently. In this report we propose a new, "metallurgical approach" to the explanation of the atomic level mechanism of $\Delta T_{\mathrm{C}}^{\mathrm{am}}$. The experimental results will be discussed on the basis of "phase reminiscence" hypotheses reported in $[1,5]$.

\section{Experiments: materials and measuring methods}

In the set of $\mathrm{Fe}_{85} \mathrm{~B}_{15} \mathrm{Si}_{x} \quad(x: 0-10)$ samples the $\mathrm{B} / \mathrm{Si}$ ratio was gradually altered. In the samples of $\mathrm{Fe}_{85-x} \mathrm{Me}_{x} \mathrm{~B}_{15}$ the Fe host was replaced by $\mathrm{Pt}$ or Cr metals. VSM magnetometer was used for the $T_{\mathrm{C}}^{\mathrm{am}}$ determination. Two types of "irreversible relaxation" are treated. First is "self relaxation" when the sample is heated for the $T_{\mathrm{C}}^{\mathrm{am}}$ measurements, other is $T_{\mathrm{C}}^{\mathrm{am}}$ shift due to the store of samples at $78 \mathrm{~K}$ for $24 \mathrm{~h}$ prior to the $T_{\mathrm{C}}^{\mathrm{am}}$ measurements. Ensuring the identical sample history the samples were prepared by the same cooling rate [6]. The heating and cooling program was also identical during the $T_{\mathrm{C}}^{\mathrm{am}}$ measurements.

\section{Results and discussion}

3.1. Alloying effects and the sign of irreversible $\Delta T_{\mathrm{C}}^{\mathrm{am}}$ The continuous change of net magnetic moment in glassy alloys formed between the $3 d$-transition metals is sufficiently explained by the itinerant electron model [7]. In contrast, the $T_{\mathrm{C}}^{\mathrm{am}}$ is highly structure sensitive and several anomalies exist which cannot be explained based on solely compositional factors [8]. Some effects in the field of host-metal replacement also hint to hidden structure-dependent factors around the eutectic composition, as it is depicted in Fig. 1. When the Fe is replaced by 5 at.\% $\mathrm{Ni}$ in hypoeutectic $\mathrm{Fe}_{85} \mathrm{~B}_{15}$, the $T_{\mathrm{C}}^{\mathrm{am}}$ suddenly increases. In contrast, the same quantity of $\mathrm{Ni}$ has practically no influence on the $T_{\mathrm{C}}^{\mathrm{am}}$ of $\mathrm{Fe}_{80} \mathrm{~B}_{20}$.

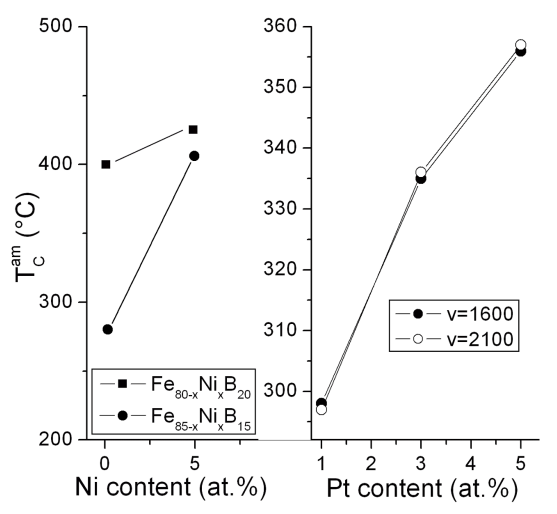

Fig. 1. The $T_{\mathrm{C}}^{\mathrm{am}}$ of $\mathrm{Fe}_{80} \mathrm{~B}_{15}, \mathrm{Fe}_{80} \mathrm{Ni}_{5} \mathrm{~B}_{15}, \mathrm{Fe}_{75} \mathrm{~B}_{20}$, $\mathrm{Fe}_{75} \mathrm{Ni}_{5} \mathrm{~B}_{20}$ and $\mathrm{Fe}_{85-x} \mathrm{Pt}_{x} \mathrm{~B}_{15}$ glasses.

The effect is similar, when the Fe is replaced by $\mathrm{Pt}$ in $\mathrm{Fe}_{85} \mathrm{~B}_{15}$ glass, which is even more surprising, because of the absence of eigen magnetic moments on Pt atoms. One can suppose the enrichment of $\mathrm{Pt}$ atoms in Fe-rich (boron-depleted) clusters, increasing the strength of average exchange interaction, via the increasing distance 
between the Fe-atoms. The importance of the "structural factors" is suspected on the basis of $T_{\mathrm{C}}^{\mathrm{am}}$ dependence on $\mathrm{Si}$ content in $\mathrm{FeB}_{15} \mathrm{Si}_{x}$ glasses (Fig. 2). The anomalous con- centration dependence of $T_{\mathrm{C}}^{\mathrm{am}}$ in $\mathrm{Fe}_{100-x} \mathrm{~B}_{x}$ is conserved, when the B atoms are replaced by Si. The irreversible $\Delta T_{\mathrm{C}}^{\mathrm{am}}$ relaxation is positive in the whole system.

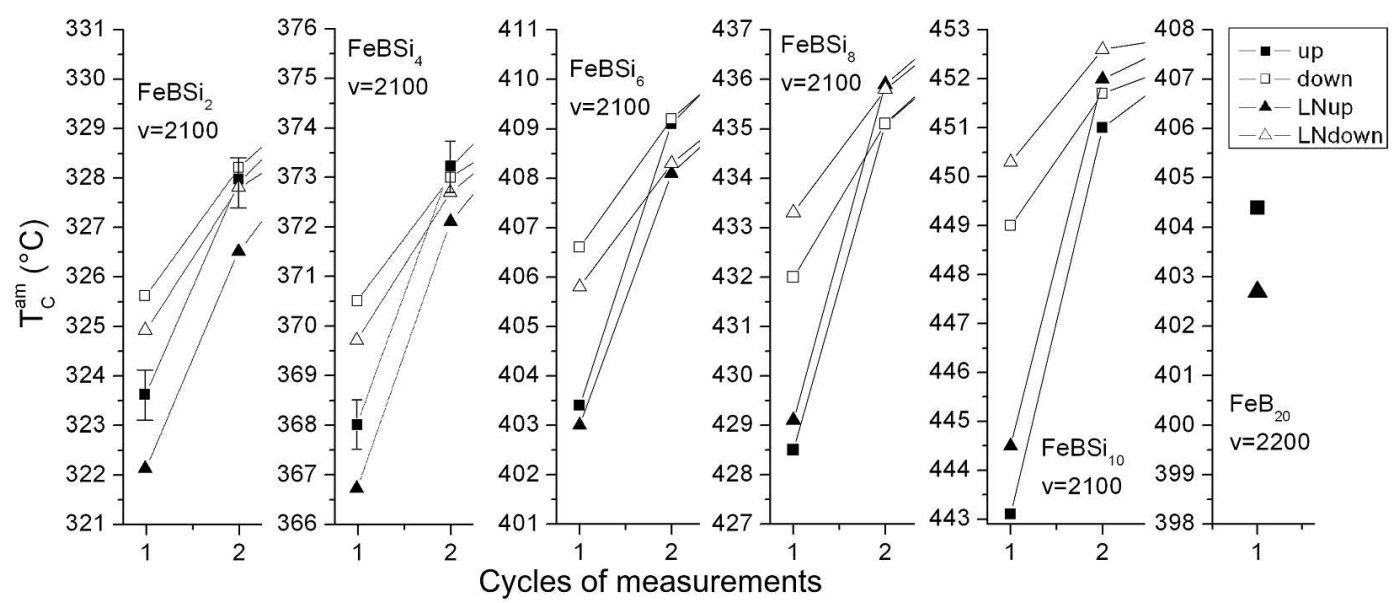

Fig. 2. The $T_{\mathrm{C}}^{\mathrm{am}}$ of $\mathrm{FeB}_{15} \mathrm{Si}_{x}$ samples during two subsequent measuring runs determined on the heating and cooling sides, respectively.

In contrast to the presented examples in Figs. 1 and 2, the $T_{\mathrm{C}}^{\mathrm{am}}$ of as-quenched glasses decreases when the Fe host metal is replaced by Cr-atoms at constant metalloid content (Fig. 3).

When the sign of alloying induced shifts is compared from the point of view of irreversible $T_{\mathrm{C}}^{\mathrm{am}}$ relaxation, one can conclude that those of alloying elements, which increase the $T_{\mathrm{C}}^{\mathrm{am}}$ (compared to the appropriate binary $\mathrm{Fe}_{85} \mathrm{~B}_{15}$ glass), also exhibit positive $\Delta T_{\mathrm{C}}^{\mathrm{am}}$ during the initial period of irreversible relaxation. The same correlation exists with the opposite sign in the case of $\mathrm{Cr}$ addition ( $\mathrm{Cr}$ causes $T_{\mathrm{C}}^{\mathrm{am}}$ lowering in $\mathrm{Fe}_{100-x} \mathrm{~B}_{x}$, so the sign of $\Delta T_{\mathrm{C}}^{\mathrm{am}}$ is negative at the beginning of relaxation, Fig. 3). The present observations are in agreement with the results reported in Ref. [3].

\subsection{Connection between the glass transition} temperature $\left(T_{\mathrm{g}}\right)$, the shape of binary FeA (A: alloying element) phase diagram, and the sign of irreversible

$$
\Delta T_{\mathrm{C}}^{\mathrm{am}} \text { relaxation }
$$

As it is shown in Figs. 2 and 3, the sign of irreversible $\Delta T_{\mathrm{C}}^{\mathrm{am}}$ can be either positive or negative $[3,5]$. The effect itself appears in the first period of heat treatment. In this heat treatment period enthalpy release and density increase can also be observed. These findings contradict with the Bethe-Slater conception, which predicts the volume expansion of Fe atoms, when the strength of ferromagnetic exchange increases [9]. It means that local packing-density decrease should admit, whilst simultaneous global, irreversible densification proceeds in the sample. The required thermal activation for this local expansion is supplied itself by the temperature increase, when the $T_{\mathrm{C}}^{\mathrm{am}}$ is measured (Fig. 2). In order to predict the actual sign of $T_{\mathrm{C}}^{\mathrm{am}}$ shift in a given temperature range,

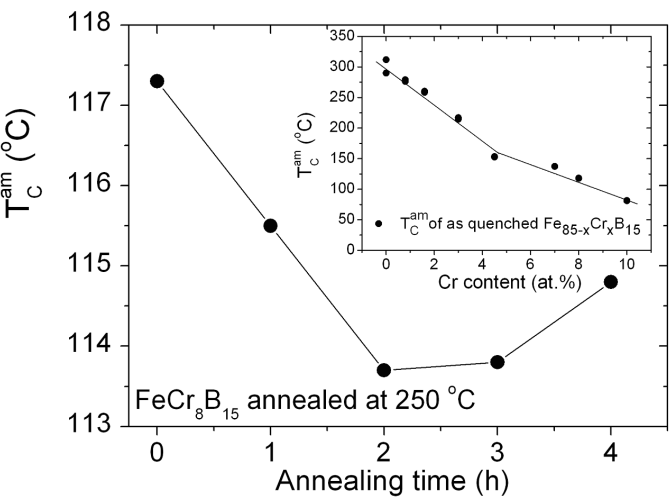

Fig. 3. The "anomalous $T_{\mathrm{C}}^{\mathrm{am}}$ relaxation" of $\mathrm{FeCr}_{8} \mathrm{~B}_{15}$ glassy alloy during isotherm heat treatment at $250^{\circ} \mathrm{C}$ (inset: $T_{\mathrm{C}}^{\mathrm{am}}$ dependence on $\mathrm{Cr}$ concentration in as quenched state).

the shape of the appropriate equilibrium phase diagrams, as well as some peculiarities of glass transition have to be considered:

The global slow down of translation atomic motions in the glass forming liquids is completed around the glass transition $\left(T_{\mathrm{g}}\right)$. Though the mobility in certain atomic environments may exhibit a great variety in the supercooling melts or, even in the frozen (glassy) state according to the energy-landscape model [10]. This model predicts the existence of weak bonding in certain atomic clusters in the glass, formed from "fragile melts". The investigated glasses are typical "weak glass formers" $\left(\mathrm{Fe}_{80} \mathrm{Ni}_{5} \mathrm{~B}_{15}, \mathrm{FeCrB}_{15}, \mathrm{FePtB}_{15}\right)$ [11]. As the temperature increases (the first period of structural relaxation), 
these mobile groups (hot points) are gradually activated. In the hypoeutectic glasses, the weak bonds are localized in the clusters in off-stoichiometric regions with low metalloid content. This is supported by the two-step crystallization mechanism in these glasses ( $\alpha$-Fe-based solid solution has started in the first crystallization step).

As the supercooling increases during the melt cooling, a kinetic competition fcc and bcc type clusters has developed, preparing the nucleation of stable phases prior to the actual critical nuclei formation. This competition leads to the development of a mixture of fcc and bcc type clusters (pre-critical nuclei, being frozen, as the $T_{\mathrm{g}}$ is approached [12]):

$$
[\mathrm{Fe},(\mathrm{TM}, \mathrm{B})] \mathrm{bcc} \leftrightarrow[\mathrm{Fe},(\mathrm{TM}, \mathrm{B})] \mathrm{fcc} .
$$

The ratio of $[\mathrm{Fe},(\mathrm{TM}, \mathrm{B})] \mathrm{bcc} /[\mathrm{Fe},(\mathrm{TM}, \mathrm{B})]$ fcc clusters is influenced by the quenching rate and the composition (according to the stability region induced by the components). The sign of $T_{\mathrm{C}}^{\mathrm{am}}$ shift with raising temperature is governed by "short range symmetry changes" including the first atomic coordination around Fe atoms (displacements requiring increasing thermal activation). The driving force between these fcc/bcc type rearrangements assigned as "hot points" (which are frozen at the $T_{\mathrm{g}}$ ) represents relative instability in the vicinity of room temperature.

As a consequence, the sign (direction) of $T_{\mathrm{C}}^{\mathrm{am}}$ shift is governed by two basic parameters: the temperature difference between the $T_{\mathrm{g}}$ and the actual temperature, at which the elementary relaxation step has started or proceeds when the sample is heated when the $T_{\mathrm{C}}^{\mathrm{am}}$ is measured. At low temperature enough, the bcc phase is stable in all alloys investigated. Hence, predominantly "fcc-to-bcc like" symmetry changes occur at low temperatures (well below to $T_{\mathrm{g}}$ ). This tendency favours the increasing strength of ferromagnetic coupling. This tendency is magnetically overcompensated by the $\mathrm{Cr}$ addition (8 at.\%) due to the preferential solubility of $\mathrm{Cr}$ in the bcc-environments. Therefore, the fcc to bcc symmetry change may result in a transient $T_{\mathrm{C}}^{\mathrm{am}}$ lowering in the very beginning heat treatments at low temperatures (Fig. 3)

\section{3. $T_{\mathrm{C}}^{\mathrm{am}}$ shift caused by low temperature store of samples $(78 \mathrm{~K})$}

This effect is reported recently by several papers, e.g. in Ref. [13]. The sample storage at low temperature such as $77 \mathrm{~K}$, may also cause Curie point shift and the sign of $\Delta T_{\mathrm{C}}^{\mathrm{am}}$ is also composition dependent. For example, the reversal of sign (at around 20 at.\% metalloid content) is found when the Si content was increased in the FeBSi glasses. The shift can be explained by the same mechanism as it was outlined above. An additional consideration has to be made however:

Glass transition follows the same mechanism as the martensitic transformation in steels (non-diffusive transformations). The common feature of these transformations is that martensitic transformation is not necessarily completed around room temperature in alloys with high metalloid content. Similarly the glass transition is not fully completed at $T_{\mathrm{g}}$ in the case of weak glass formers. Therefore, the $T_{\mathrm{C}}^{\mathrm{am}}$ shift due to low temperature treatments can be regarded as a shear-induced perfection of the glass transition. The more elaborated version of this conception is going on.

\section{Conclusions}

1. Correlation was found between the sign of Curie-point shifts caused by the alloying, and induced by the irreversible structural relaxation observed during the subsequent measuring runs. Those of alloying elements which cause $T_{\mathrm{C}}^{\mathrm{am}}$ increase compared to the as quenched binary $\mathrm{Fe}-\mathrm{B}$ glass (at the same $\mathrm{B}$ content!) also exhibit positive, irreversible $T_{\mathrm{C}}^{\mathrm{am}}$ increase during first period of relaxation heat treatments. In contrast, the $\mathrm{Cr}$ addition has an opposite effect.

2 . The $\Delta T_{\mathrm{C}}^{\mathrm{am}}$ induced by low temperature sample storage can be qualitatively explained by the shear induced completion of glass transformation.

3. The tendencies are explained on the basis of competing stability of the quenched-in bcc or fcc like environments (phase reminiscences) reported in earlier papers.

\section{Acknowledgments}

This work has been supported by the Hungarian Scientific Research Fund (OTKA) through grant No. K-73690.

\section{References}

[1] K. Bán, A. Lovas, J. Kováč, L. Novák, Berichte und Informationen (2006) 14 Jahrgang, Proc. 23rd Int. Colloquium, May, 10-12 2006, Kollm, p. 67.

[2] J.O. Ström-Olsen, R. Brüning, Z. Altounian, D.H. Ryan, J. Less-Common Met. 145, 4 (1988).

[3] P. Németh, A. Böhönyey, G. Tichy, L.F. Kiss, J. Magn. Magn. Mater. 320, 719 (2008).

[4] T. Tarnóczi, A. Lovas, C. Kopasz, Mater. Sci. Eng. 97, 509 (1988).

[5] J. Kováč, B. Vehovszky, L. Novák, A. Lovas, IEEE Trans. Magn. 46, 353 (2010).

[6] A.L. Greer, J. Mater. Sci. 17, 1117 (1982).

[7] E.P. Wohlfarth, Amorphous Metallic Alloys, Ed. F.E. Luborsky, BMM Butterworths Monogr. in Mat., Butterworths, London 1983, p. 283.

[8] A. Lovas, É. Kisdi-Koszó, L.K. Varga, J. Kováč, Key Eng. Mater. 81-83, 607 (1993).

[9] D. Jiles, Introduction to Magnetism and Magnetic Materials, Chapman \& Hall, London 1998.

[10] P.G. Debenedetti, F.H. Stillinger, Nature 410, 259 (2001).

[11] U. Köster, R. Janlewing, Mater. Sci. Eng. A 375-377 223 (2004).

[12] A. Lovas, L. Novak, J. Kovac, S. Balla, Open Macromol. J., to be published.

[13] G. Zaichenko, N.S. Perov, A.M. Glezer, E.A. Ganshina, V.M. Kachalov, M. Calvo-Dalborg, U. Dalborg, J. Magn. Magn. Mater. 215-216, 297 (2000). 